\title{
Generating two-monthly surface water images for the Murray-Darling Basin
}

\author{
C.J. Ticehurst $^{\text {a }}$, J. Teng a and A. Sengupta ${ }^{\text {a }}$ \\ ${ }^{a}$ CSIRO Land \& Water, Canberra, Australian Capital Territory \\ Email: catherine.ticehurst@,csiro.au
}

\begin{abstract}
Mapping surface water extent is an important step in estimating water volume within a catchment, which is needed for managing flood events, as well as water supply for human consumption, agriculture, and the environment. Satellite-based remote sensing technologies provide an affordable means of capturing surface water extent with reasonable spatial and temporal coverage suited to the purpose of water monitoring. A new multi-index method (MIM) has been developed for mapping surface water across the Murray-Darling Basin (MDB) based on Landsat surface reflectance data available in Digital Earth Australia. More than thirty years of two-monthly images of surface water extent across the whole MDB have been produced using this method, along with Water Observations from Space (WOfS) to fill in any gaps associated with cloud cover due to the different cloud masks used (this combined product is referred to as MIM_WOfS_max). This product is currently being combined with a DEM to produce estimates of water depth across the basin and can be used with hydrology models for assessing connectivity between waterbodies. This product can also be used to assess long-term trends of surface water extent across the basin, as well as used for seasonal or bi-monthly analysis.

The methods used to produce the two-monthly WOfS and MIM products across the MDB are different and were based on utilizing the available cloud masks attached to the native products, and computational efficiency for generating the products. A comparison of the MIM and WOfS method shows that MIM identifies major perennial rivers and wetlands better than WOfS, as well as in some of the floodplain areas, while WOfS can identify more surface water in general areas where cloud cover still exists in the MIM product. A small misregistration (up to 30 metres in some areas) between the MIM and WOfS products was also found - possibly due to the different native spatial projections of the datasets.

The MIM_WOfS_max product is used for identifying long-term and seasonal trends across the MDB. Over the 33-year time period (1988 to 2020) a reduction in surface water extent of $0.15 \%$ was found for the whole basin. The long-term trends of four sites were also investigated: two irrigated regions and two wetlands. They also showed a long-term reduction in surface water extent. The southern sites (one irrigated agriculture and one wetland) had regular annual flooding which gradually reduces in size through time, while the northern sites showed irregular flood patterns - with respect to the flood's timing and magnitude.

Details of the method used and challenges associated with producing the bi-monthly images of surface water across the MDB are provided in the paper, as well as further discussions on some of the long-term and seasonal trends that can be derived from this product for the entire MDB and selected regions within.
\end{abstract}

Keywords: $\quad$ Surface water extent, remote sensing, Murray-Darling Basin 


\section{INTRODUCTION}

Mapping surface water extent is an important step in estimating water volume, and monitoring these changes is necessary for managing water supply for human consumption, agricultural use, as well as maintaining the environmental health of wetlands and rivers. A growing population and changing climate are leading to increased pressure on water supply, meaning accurate information on available water is vital. This is particularly so in much of Australia, which is becoming hotter and dryer in recent times (Commonwealth of Australia 2021a). Furthermore, with flood frequency likely to increase as a result of environmental changes (Karamouz et al. 2011; Bhuiyan and Dutta 2012; Teng et al. 2012), there is a growing demand for accurate flood maps for disaster risk management.

Ground observations of surface water extent can provide valuable information, but are not always available. It is also difficult to obtain large scale synopsis of current and historical water extent through gauging stations and high water marks. Remote sensing technologies provide an affordable means of capturing surface water extent with reasonable spatial and temporal coverage suited to the purpose of water monitoring. The spatial resolution of the Landsat satellite series $(30 \mathrm{~m})$ makes it suitable for capturing much of the fine spatial detail of a large river basin (e.g. Pekel et al. 2016), at a temporal scale of 16 days (subject to cloud cover). It also has a rich archive of data dating back to 1987 for the thematic mapper series.

The Water Observations from Space dataset is generated by Geoscience Australia and available through Digital Earth Australia (Mueller et al. 2016). WOfS uses a decision tree approach based on a selection of Landsat spectral bands and indices, as well as ancillary products (including topography and hydrology layers) to constrain water extent to likely areas. Individual WOfS images of surface water extent, along with summary statistics (from 1980's to present) are available for Australia for the whole Landsat archive. The WOfS data was designed to provide a conservative estimate of surface water extent, making it a robust product, but it is more likely to underestimate, rather than overestimate water extent (Sims et al. 2016). However, its cloudmasking layer works well, with very low commission errors.

A multi-index method (MIM) was developed for mapping surface water extent within the Murray-Darling Basin (Ticehurst et al. in review). It is based on existing indices: modified Normalised Difference Water Index (mNDWI; Xu 2006), Fisher's water index (FWI; Fisher et al. 2016), and the Tasseled Cap Wetness Index (TCW; Dunn et al. 2019) already used for mapping surface water extent, where each index is applied in the area where it performs at its best. The resulting rule-set uses the NDWI $>-0.3$ to map water in major perennial rivers, TCW $>-0.035$ to map water in wetlands, and the maximum of $\mathrm{NDWI}>0$ and $\mathrm{FWI}>0.63$ for mapping water in the remaining areas. Based on 440 validation plots in the Murray-Darling Basin, this resulted in an overall balanced accuracy of $92.7 \%$.

\section{STUDY SITE}

The MDB is located in south-eastern Australia (Figure 1). It covers an area more than one million square kilometres, with 40,000 kilometres of major rivers (Commonwealth of Australia 2021b). The MDB contains over 30,000 wetlands, with 16 of those being internationally significant. It also produces around $40 \%$ of Australia's agricultural produce (MDBA 2021). The northern section of the MDB consists of mostly unregulated ephemeral rivers and streams, while the southern section contains mostly regulated rivers with major water storages in many of them (Commonwealth of Australia 2021b).

\section{DATA AND METHOD}

Landsat data from 1988 to 2020 were extracted and processed using Digital Earth Australia (DEA; Dhu et al. 2017, Australian Government 2021) as analysis-ready Landsat surface reflectance. The MDB covers 62 individual Landsat path/row scenes. WOfS water maps were also available through Digital Earth Australia.

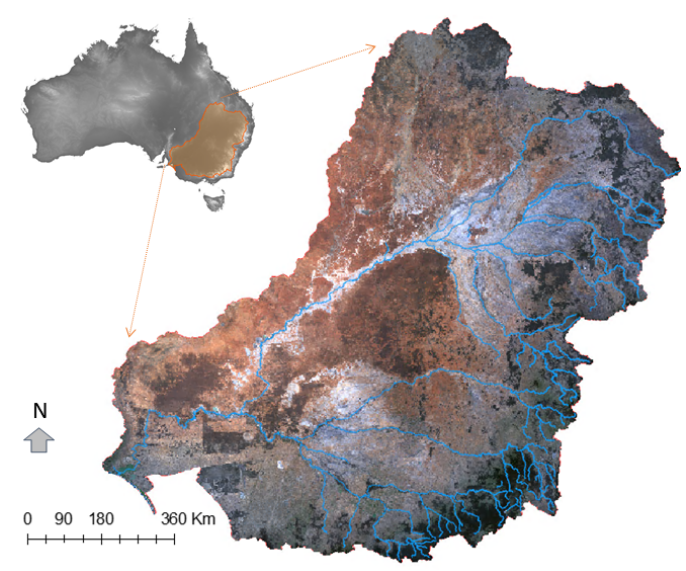

Figure 1. Location of the Murray-Darling Basin within Australia. Blue lines show perennial rivers overlaid on Landsat 8 geo-median image from Digital Earth Australia. 
Processing was performed on the Australian National Computational Infrastructure (NCI Australia 2021) using Virtual Desktop Infrastructure (VDI), tested using jupyter notebooks, and batch-processed as python scripts.

The method for extracting data within DEA was different for Landsat surface reflectance and WOfS. This was due to the different way that Landsat surface reflectance and WOfS have cloud masking applied. Landsat surface reflectance uses the standard Fmask layer (Zhu and Woodcock 2012), while WOfS uses Fmask as well as the automatic cloud cover assessment method (Irish 2000) to further reduce the chance of remnant cloud or cloud shadow in the imagery.

For WOfS, images within a degree tile (latitude and longitude) covering the MDB for every two months were extracted, and the maximum water extent maps produced. The MIM water images require six Landsat bands: blue, green, red, near-infrared and the two shortwave infrared bands. These Landsat images were extracted using DEA's load_ard function (Geoscience Australia 2021) as third-of-a-degree tiles (which will now be called a sub-tile). This function is an efficient way of reading Landsat data as it extracts from all relevant sensors (Landsat Thematic Mapper (5), Enhanced Thematic Mapper (7) and Operational Land Imager (8)) within the specified time period. Each sub-tile was chosen to be one third of a degree extent in latitude and longitude as it reduced the computing memory requirements (since six bands are required for producing the multi-index method water map), making it fast, and to help reduce remnant cloud cover/shadow being included. This is because cloud shadow can have a very similar spectral response to water, resulting in incorrect estimates of maximum water extent within the sub-tile. The load ard function has an option of specifying the maximum percentage of cloud cover (based on Fmask) allowed to be extracted from images within the defined extent. A threshold of $20 \%$ cloud cover was chosen, so only images that are at least $80 \%$ cloud free within the sub-tile were used in creating maximum surface water extent. Hence, the load_ard function works better on smaller tiles when this cloud cover threshold is utilised. All tiles were then merged for every two months for both the WOfS and MIM products.

All of the MIM two-monthly water images were visually inspected for any remaining artefacts, with cloud cover/shadow being the main culprit, which were manually masked from that image. However, some small artefacts remain as they were not visible when looking at the image at a regional scale - and inspecting all areas in all images in detail was not feasible. Snow was also being identified as surface water, so a snow zone mask was created for the alpine region and applied to the two-monthly images for the colder months (i.e. MayJune, July-August, September-October). Three large lakes exist within the snow zone, which were not included in the snow mask. Instead, they were inspected to make sure they appeared to be free of snow and only manually masked if needed.

To minimise null values and maximise surface water extent for every two months, the maximum water extent was calculated from the MIM and WOfS products. Pixels of null values (which were due to cloud masks or no data) were replaced with the other data product. The 33 years of this new two-monthly product (called the MIM_WOfS_max) were combined to create an image of the percentage of time (i.e. based on each twomonthly period) that a pixel is wet. An equivalent product was also generated from the two-monthly MIM images and the two-monthly WOfS images, and compared between them.

The MIM_WOfS_max product is then used to explore long-term and seasonal trends across the basin as well as two irrigated agriculture sites (the Coleambally Irrigation Area and lower Balonne floodplain) and two wetland sites (Barmah forest and Macquarie Marshes) (See Figure 2a for locations).

\section{RESULTS}

The percentage of observations that a pixel has water in it, based on the two-monthly MIM_WOfS_max from 1988 to 2020, is shown in Figure 2a. This is similar to Geoscience Australia's WOfS summary layer (Mueller et al. 2016), but with some minor differences due to the rule set used to produce the multi-index method product. Figure $2 \mathrm{~b}$ shows the difference between the percentage of time that a pixel has water in it based on the two-monthly MIM and the two-monthly WOfS products. Blue and green colours show where the multiindex method identifies more water, while red and orange colours show where WOfS does. In general, major perennial rivers can show as slightly wider and/or more frequently detected in the MIM product (Figure 2c). However, there is also a slight mis-match between the MIM and WOfS two-monthly products in some areas up to one Landsat pixel $(\sim 30 \mathrm{~m})$ (see top left corner of Figure $2 \mathrm{c})$. This mis-match occurs even when the Landsat surface reflectance and WOfS DEA products are extracted the same way, but may be related to their different native projections within the DEA. (The latest Landsat surface reflectance used here is collection 3 in Universal Transverse Mercator (UTM) projection, while the WOfS two-monthly product was generated before collection 3 was available and is Albers Equal Area projection). 
The MIM method identifies more water in flooded wetlands compared to WOfS, as can be seen in the Barmah Forest (Figure 2d). Both Figure 2c and Figure 2d show areas where MIM identifies more water (light green tones) and other areas where WOfS identifies more water (light orange tones) across the general landscape. This is most likely due to the different cloud-masking algorithms available within each of the DEA datasets. All available WOfS images were used to create maximum water extent, whereas only the Landsat surface reflectance with less than $20 \%$ cloud cover were extracted within each sub-tile. Despite these issues, the MIM_WOfS_max product is useful for combining with a DEM for water volume estimates, as input to inundation models, and for investigating trends and spatial patterns of water across the MDB.

Percentage of water within the MDB for each two-monthly MIM_WOfS_max image was calculated, and those images with a low proportion of null values $(<5 \%)$ shown in Figure 3 . There were periods of large flood events in 1990, 1998, 2011 and 2016, although the catchments where flooding occured requires inspection of individual images. The long-term trend shows a reduction in total surface water across the MDB. Over the 33year period, this reduction is approximately $0.15 \%$ of the basin extent.

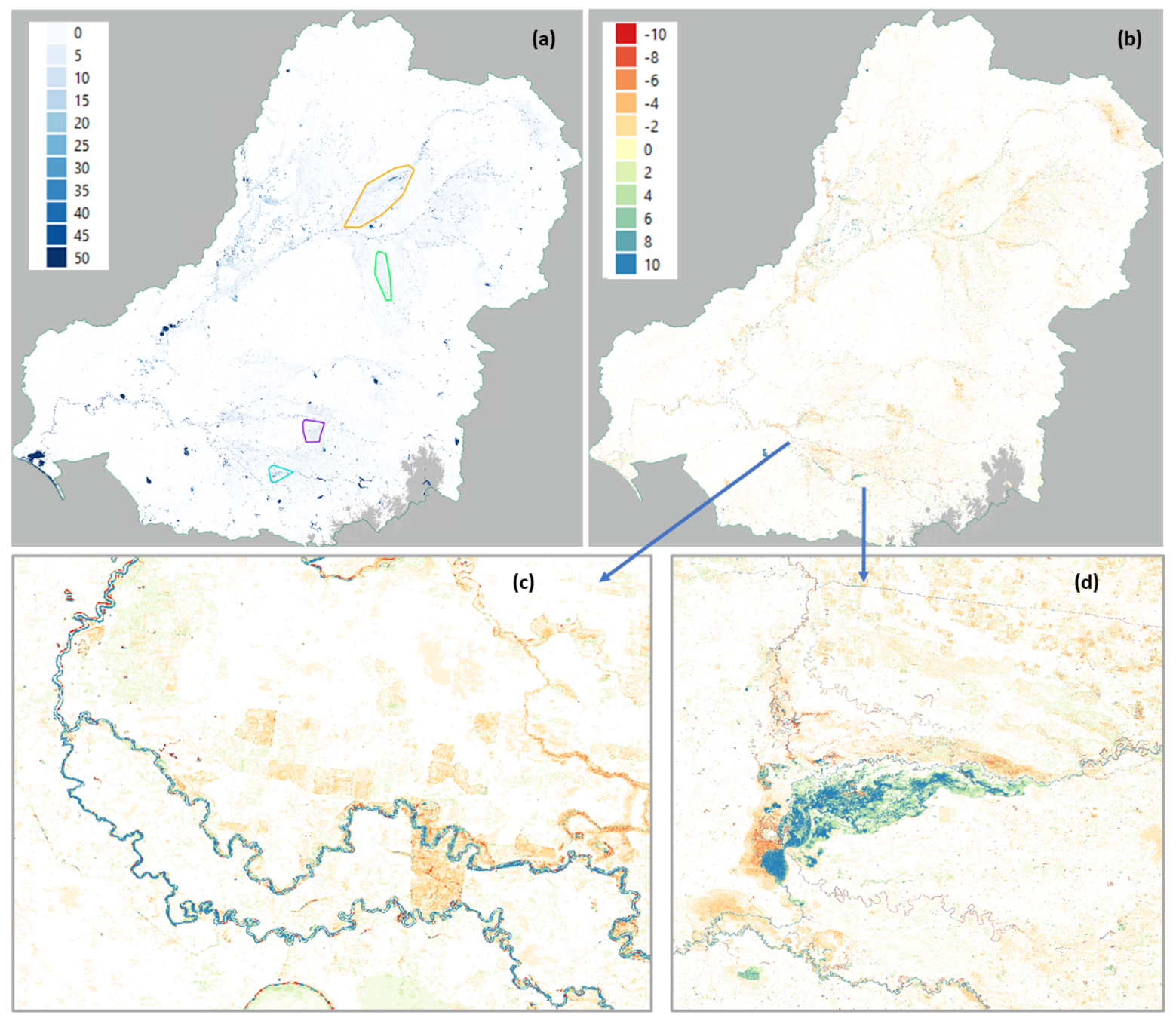

Figure 2. (a) The percentage of observations that a pixel has water in it, based on the twomonthly MIM_WOfS_max from 1988 to 2020 for the Murray-Darling Basin. (b) difference between MIM and WOFS percentage of observations that a pixel has water in it (based on twomonthly images) for the Murray-Darling Basin. (c) subset of (b), (d) subset of (b). Coleambally

Irrigation Area (purple), lower Balonne floodplain (orange), Barmah forest (cyan) and Macquarie Marshes (green) are also shown in (a).

The two-monthly image containing minimum water extent and maximum water extent for each year was calculated (Figure 4). Figure 4a shows surface water extent tends to be lowest during the winter months, based on the whole MDB. Surface water extent tends to be at a maximum during the months of January-February, 
and September-October. This water extent not only includes flooding, but also irrigated fields and storage tanks. No long-term trends can be seen in either of these plots.

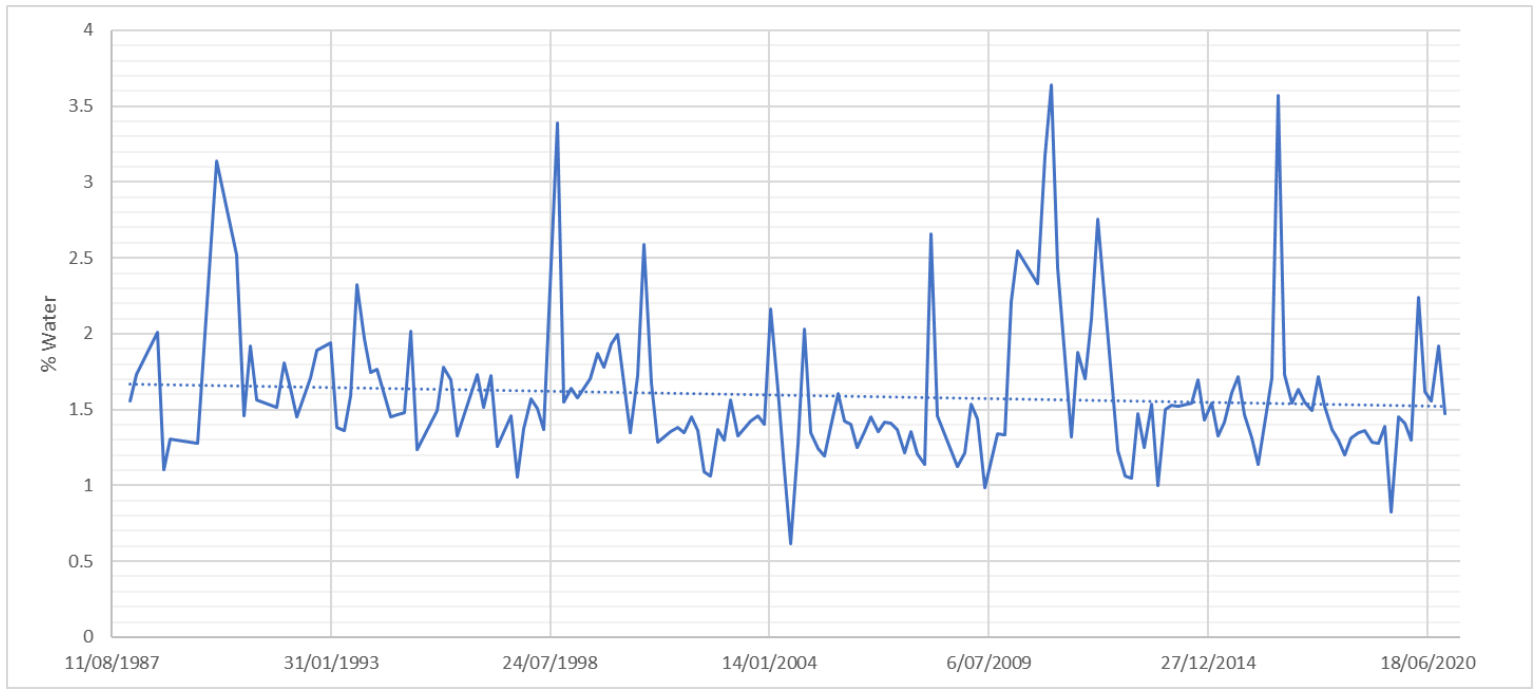

Figure 3. Percentage of water pixels within the Murray-Darling Basin generated from mostly cloud-free two-monthly MIM_WOfS_max product. Long-term trend shown in dashed line.

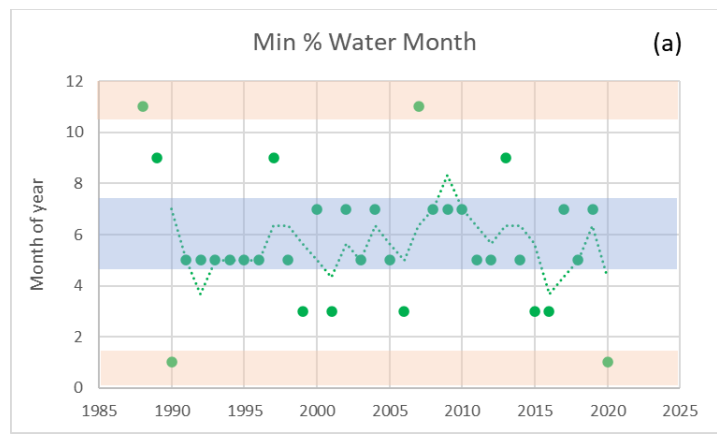

(a)

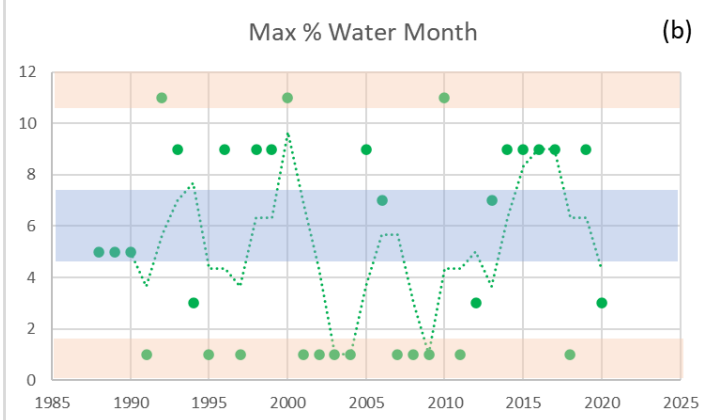

Figure 4. Month containing minimum (a) and maximum (b) water extent for each year for the Murray-Darling Basin based on the MIM_WOfS_max product.

The total percentage of water within four sites for the two-monthly MIM_WOfS_max images was calculated, and those images with a low proportion of null values $(<5 \%)$ shown in Figure 5 . Two of these areas cover irrigated agriculture (Coleambally Irrigation Area and irrigated cotton in the lower Balonne floodplain) and two areas cover wetlands (Barmah Forest and Macquarie Marshes) (See Figure 2a for locations). The longterm trend shows a reduction in water extent for all sites over the 33-year period. It also shows different types of flooding occurs in these different sites. Barmah forest shows regular flooding each year in September which starts to drop off from 1994. The Coleambally Irrigation Area shows regular flooding each year around September-October and November-December which reduces substantially around 2002 dropping away completely from 2007 until 2010. The Macquarie Marshes in the northern part of the basin show less regular flooding, but with some very large flood events. This pattern is also seen in the other northern site at the lower Balonne floodplain.

\section{DISCUSSION AND CONCLUSION}

Landsat data provided through a nation-wide data cube such as in Digital Earth Australia, can be used to provide multi-temporal images of surface water extent at reasonable spatial and temporal resolution for monitoring water dynamics in a large regional catchment such as the MDB. In this paper, Landsat data within Digital Earth Australia were used to generate two-monthly images of maximum water extent from 1988 to 2020. The new MIM was combined with the WOfS dataset to produce a new product providing maximum twomonthly water extent, while minimizing data gaps due to cloud cover or null data values. The use of MIM provides better identification of major rivers and flooded wetlands, while inclusion of the WOfS increases the chances of finding more cloud-free observations. While the details are not included in this paper, the multiindex method has been tested for its ability to identify water within the MDB with an accuracy of $92.7 \%$, which 
is higher than the individual water indices that it uses (Ticehurst et al. in review). This MIM_WOfS_max product can be used to provide summary statistics across the basin, including long-term trends of surface water extent for the whole basin, or individual sites within the basin. All sites examined in this paper showed a longterm reduction in surface water extent. It must be noted that a maximum two-monthly product is not necessarily going to give an accurate indication of minimum water extent during dryer periods, as it was designed to maximise the chances of capturing flood events by generating maximum extent. Any cloud cover during a flood event, which often occurs, will reduce any observation of the actual flood extent. However, these types of products provide basis to estimate water depth across the MDB and can be used in conjunction with hydrology models to investigate floodplain connectivity and water movement in a complex environment.

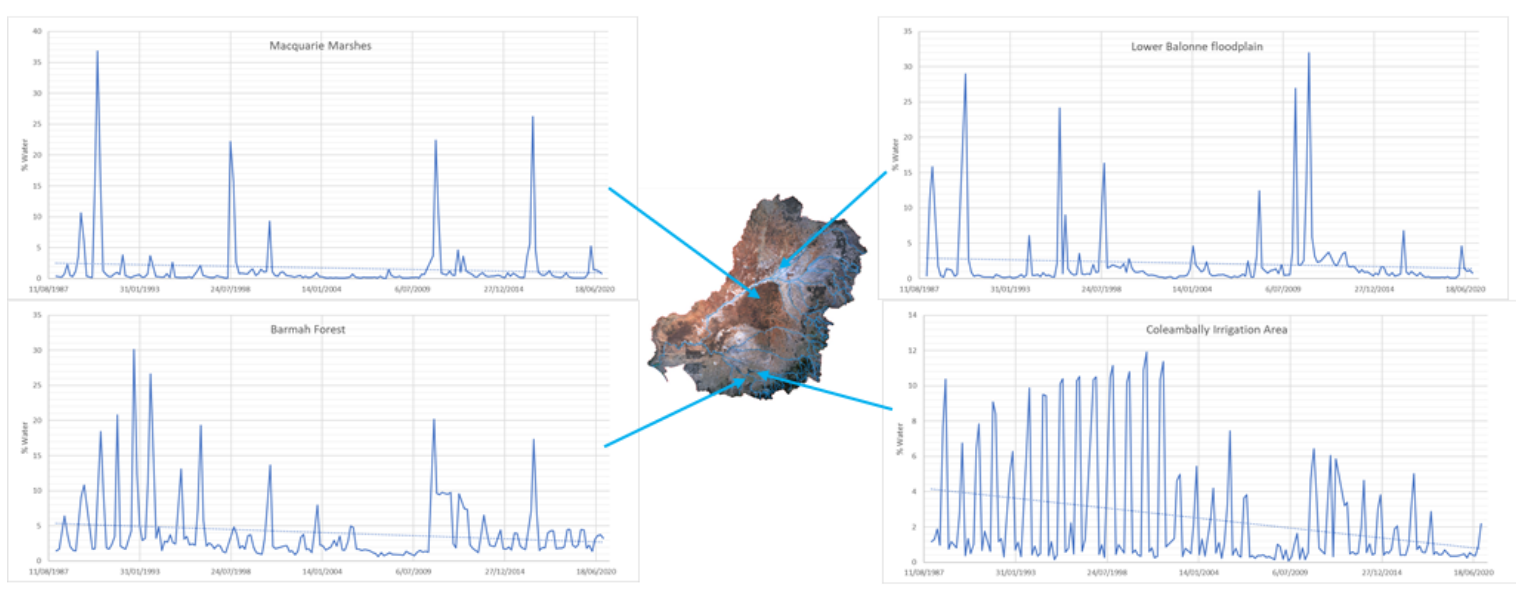

Figure 5. Percentage of water pixels within the areas around Macquarie Marshes, Barmah Forest, Lower Balonne floodplain and Coleambally Irrigation Area generated from mostly cloudfree two-monthly MIM_WOfS_max product. Long-term trend shown in dashed line

\section{ACKNOWLEDGMENTS}

This work has been supported through the project Investing in new knowledge to evaluate and adapt the 2012 Murray-Darling Basin Plan.

\section{REFERENCES}

Australian Government, Geoscience Australia, 2021. Digital Earth Australia. https://www.ga.gov.au/dea/home. Accessed 5 August 2021.

Commonwealth of Australia, Bureau of Meteorology, 2021a State of the Climate 2020. http://www.bom.gov.au/state-of-the-climate/. Accessed 4 August 2021.

Commonwealth of Australia, Bureau of Meteorology, 2021b. National Water Account 2020, Murray-Darling Basin: Geographic information. http://www.bom.gov.au/water/nwa/2020/mdb/regiondescription/geographicinformation.shtml\#geographic information. Accessed 5 August 2021

Crist, E.P., 1985. A TM Tasseled Cap equivalent transformation for reflectance factor data. Remote Sensing of Environment, 17(3), 301-306.

Bhuiyan, J., and Dutta, D., 2012. Analysis of Flood Vulnerability and Assessment of the Impacts in Coastal Zones of Bangladesh due to Potential Sea Level Rise. Natural Hazards, 61:729-743.

Dhu, T., Dunn, B., Lewis, B., Lymburner, L., Mueller, N., Telfer, E., Lewis, A., McIntyre, A., Minchin, S., Phillips, C., 2017. Digital earth Australia - unlocking new value from earth observation data. Big Earth Data, 1:1-2, 64-74, DOI: 10.1080/20964471.2017.1402490.

Dunn, B., Lymburner, L., Newey, V., Hicks, A., Carey, H., 2019. Developing a tool for wetland characterisation using fractional cover, Tasseled Cap Wetness and Water Observations from Space. IGARSS 2019 - 2019 IEEE International Geoscience and Remote Sensing Symposium, 2019, pp. 60956097, doi: 10.1109/IGARSS.2019.8897806.

Dutta, D., and Nakayama, K., 2009. Effects of Spatial Grid Resolution on River Flow and Surface Inundation Simulation by Physically Based Distributed Modeling Approach. Hydrological Processes, 23:534-545. 
Ticehurst et al., Generating two-monthly surface water images for the Murray-Darling Basin

Fisher, A., Flood, N., Danaher, T., 2016. Comparing Landsat water index methods for automated water classification in eastern Australia. Remote Sensing of Environment, 175, 167-182, https://doi.org/10.1016/j.rse.2015.12.055.

Geoscience Australia, 2021. Digital Earth Australia User Guide. https://docs.dea.ga.gov.au/ . Accessed 19 August 2021.

Irish, R.R., 2000. Landsat 7 automatic cloud cover assessment. In AeroSense 2000, Pages 348-355. International Society for Optics and Photonics.

Karamouz, M., Noori, N., Moridi, A., Ahmadi, A., 2011. Evaluation of floodplain variability considering impacts of climate change. Hydrological Processes, 25: 90-103

MDBA (Murray Darling Basin Authority), 2021. The Murray-Darling Basin and why its important. https://www.mdba.gov.au/importance-murray-darling-basin. Accessed 6 August 2021.

Mueller, N., Lewis, A., Roberts, D., Ring, S., Melrose, R., Sixsmith, J., Lymburner, L., McIntyre, A., Tan, P., Curnow, S., Ip, A., 2016. Water observations from space: Mapping surface water from 25 years of Landsat imagery across Australia. Remote Sensing of Environment, 174, 341-352.

NCI Australia, 2021. National Computational Infrastructure Australia. https://nci.org.au/. Accessed 5 August 2021.

Pekel, J.F., Cottam, A., Gorelick, N., Belward, A.S., 2016. High-resolution mapping of global surface water and its long-term changes. Nature 540, 418-422 (2016). https://doi.org/10.1038/nature20584.

Sims, N., Anstee, J., Barron, O., Botha, E., Lehmann, E., Li, L., McVicar, T., Paget, M., Ticehurst, C., Van Niel, T., Warren, G., 2016. Earth observation remote sensing. A technical report to the Australian Government from the CSIRO Northern Australia Water Resource Assessment, part of the National Water Infrastructure Development Fund: Water Resource Assessments. CSIRO, Australia.

Teng, J., Vaze, J., Dutta, D., Marvanek, S., 2015. Rapid inundation modelling in large floodplains using LiDAR DEM. Water Resource Management, 29(8): 2619-2636.

Ticehurst, C.J., Teng, J., Sengupta, A., in review. Application of multiple Landsat indices for mapping surface water across a complex Australian environment. Submitted to Remote Sensing.

$\mathrm{Xu}, \mathrm{H} ., 2$ 2006. Modification of normalised difference water index (NDWI) to enjance open water features in remotely sensed imagery. International Journal of Remote Sensing, 27, 3025-3033. doi: $10.1080 / 01431160600589179$.

Zhu, Z., Woodcock, C.E., 2012. Object-based cloud and cloud shadow detection in landsat imagery. Remote Sensing of Environment, 118, 83-94. 